Article

\title{
Weighing Posthumanism: Fatness and Contested Humanity
}

\author{
Sofia Apostolidou and Jules Sturm * \\ Amsterdam School for Cultural Analysis, University of Amsterdam, 1012 CX Amsterdam, The Netherlands; \\ E-Mails: s.apostolidou@uva.nl (S.A.), j.v.sturm@uva.nl (J.S.) \\ * Corresponding author
}

Submitted: 28 June 2016 | Accepted: 14 September 2016 | Published: 10 November 2016

\begin{abstract}
Our project on fatness begins by turning attention to the multiple cultural instances in which fatness has been intrinsically linked with notions such as self-neglect and poor self-management. In Foucauldian terms, we analyse the fat subject as a failed homo economicus, an individual who has failed to be an "entrepreneur of himself, being for himself his own capital, being for himself his own producer, being for himself the source of [his] earnings" (Foucault, 2008, p. 226). From this perspective, we analyse instances of collective hatred towards fat subjects as direct results of the biopolitical triplet of responsibility, rationality, and morality. Morality is our bridge into the field of posthumanism, in which, as we demonstrate, these biopolitical imperatives also apply, reinforced by the field's fascination with prosthetics and enhancement. Where, by biopolitical standards, fat subjects have failed to manage themselves, posthuman subjects find themselves guilty of not responsibly, rationally, and morally manipulating themselves to optimal productivity. Using criticism that disability studies scholars like Sarah S. Jain and Vivian Sobchack have voiced about posthumanism, we demonstrate the ways in which, within posthumanism, all subjects can be found as lacking when compared to their potential, enhanced posthuman version.
\end{abstract}

\section{Keywords}

biopolitics; disability studies; fat studies; posthumanism; prosthesis

\section{Issue}

This article is part of the issue "Humanity as a Contested Concept: Relations between Disability and 'Being Human'”, edited by Paul van Trigt (Leiden University, The Netherlands), Alice Schippers (Disability Studies in Nederland, The Netherlands) and Jacqueline Kool (Disability Studies in Nederland, The Netherlands).

(C) 2016 by the authors; licensee Cogitatio (Lisbon, Portugal). This article is licensed under a Creative Commons Attribution 4.0 International License (CC BY).

\section{Introduction}

"The writing of the posthumanist condition should not seek to fashion 'scriptural tombs' for humanism, but must, rather, take the form of a critical practice that occurs inside humanism, consisting not of the wake but the working-through of humanist discourse." (Badmington, 2003, p. 20)

When Neil Badmington (2003) suggests that we adopt a critical practice inside humanism, he hints at the possibility that posthumanism must prove itself worthy of performing such critical practices without falling into the trap of reproducing the pitfalls of humanist discourse. The following essay attempts not only to expose the danger of such pitfalls for posthumanism, but also offers ways of reflecting on contested humanity by way of engaging embodied theories. The (fat) body here does not serve as an object of study, but rather as an agent that reveals the objectifying effects of neoliberal biopolitical discourse. Fat bodies thus become part of a critical way of theorising human life from a posthumanist perspective. The fat body's relation to posthumanist theory is specific in that it poses a conceptual problem to the posthumanist's critical stance towards human embodiment and bodily enhancement. The fat body, similar to, yet different from, the generic "disabled" body cannot be enhanced by technology, as technology is widely understood, but only by moral discipline and self-management. While prosthetic enhancements are seen as an external 
"solution" to disability, the fat body needs to employ internal, moralized technologies of discipline, such as diet and exercising, in order to comply with productive normativity. Our argument in this article is that bodily enhancement (technological as well as moral) is at the core of not only humanity, but also of the seemingly critical and potentially more inclusive post-humanity. Also, that the concept of the fat body, with the help of a critically informed discourse on disability and bioethics, helps to reveal and hopefully contest the dependency of all humanity on this core.

The overall aim of this paper is to bring critical posthuman theories into productive dialogue with current social and cultural trends towards bodily "uniformity" in the name of human enhancement. This attempt not only serves as a critique of public discourses and practices by way of analysing popular websites and online forums on "fat hatred"; it also aims to bring to the fore that our contemporary bodies are subjected to a powerful machinery built on neoliberal, moralistic, and rationalist cultural ideologies that target specific bodies more than others. Motivated by a critical disability studies critique of social inequality on the basis of bodily ability, we take the marginal field of fat studies as a conceptual bridge between the discourse around typically marginalized bodies and the more general problem of the body for the constitution of all humanity or post-humanity.

The first case study used in this essay is an image taken from a website called Health Fitness Revolution $(H F R)^{1}$ (Figure 1). What is first presented to the viewer of the homepage of HFR is a series of rotating images that function as links to articles promoting fitness, phys- ical activity, and healthy nutritional habits. Articles with titles like "You Are What Your Father Eats", "Healthy VS Unhealthy Diet", "How to Live to 100", "Best Foods to Fight Fatigue", "Best Foods for Alzheimer's Disease", and "The Benefits of Biking" follow each other in a succession which, for all stated purposes, is not explicitly about or against fatness. These articles are focused on passing down the wisdom of well-being and recipes for longevity, strength, fitness, and even mental health. If anything, dieting and nutrition are props to the sacred mission of healthy living. We have chosen this website as representative of the many dedicated to the ongoing 'War Against Obesity' initiative in the United States. The article on which we have chosen to focus, titled "Tips for Overcoming a Weight Loss Plateau", delivers advice on how to successfully continue one's diet, the key word here being continue. This article targets people who are already dieting: sound, rational homines economici. If application of economic to social models is to work, its subject must be a rational homo economicus. The reader of this article is thus not addressed as potentially being a fat subject, but instead as a properly functioning individual, dedicated to maintaining his or her good health, and by extension, his or her capital. We would like to dig a bit further into what this assumption-that the visitor of the website is already a well-functioning homo economicusreveals about the mechanisms that produce the knowledge (and thus rationality) allotted to this subject as his or her primary mode of operation.

The image accompanying the article (Figure 1) depicts two men standing next to each other, one of them muscular, holding gym weights and an apple, and the

\footnotetext{
$\overline{{ }^{1} \text { http://www.healthfitnessrevolution.com }}$
}

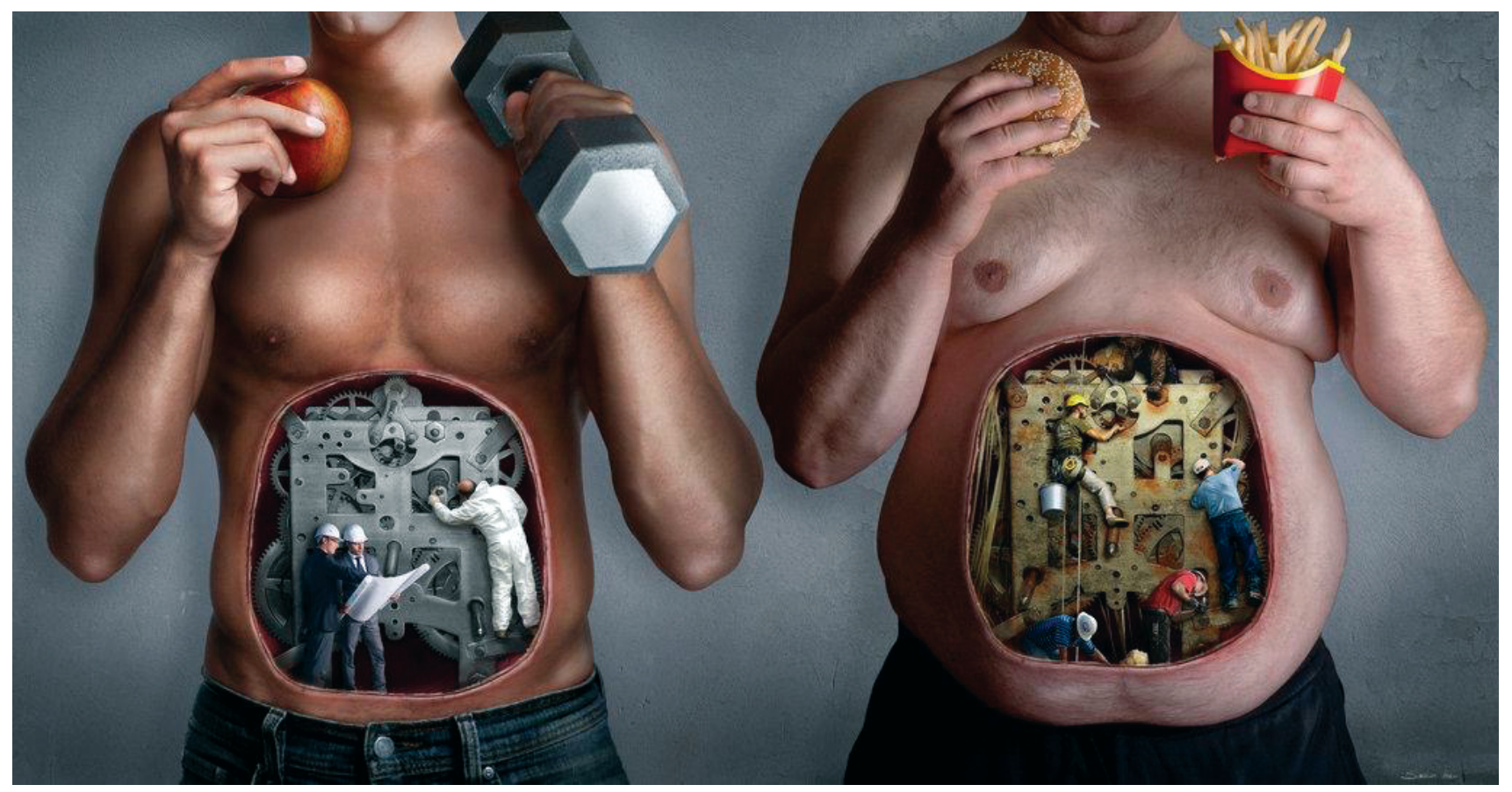

Figure 1. HFR "Tips for overcoming a weight loss plateau" (30 May 2016). 
other overweight, holding a hamburger and a package of fries. Both of the men's abdomens are hollow, and inside their bellies one can see a machine and a construction crew. The muscular man's machine is made of shiny silver. His construction crew is comprised of two welldressed men consulting a diagram and a worker, clad in a white uniform and propped up on a ladder, tinkering with some cogs in the centre. The machine in the fat man's abdomen, on the other hand, is rusty and appears dirty and neglected. The working crew is comprised of four men not in uniform, their attire dirty and worn.

The metaphors in this image suggest that if you eat well and exercise, your body will function like a well-oiled machine. By making the 'right' choices, you supply your body with the 'right' crew that will make effective, well thought-out, rational decisions in the maintenance of your body-machine, keeping it in the best possible condition. The key word is maintenance. As depicted in the image, the machine already appears to function well, needing only minimal tinkering from the worker. If, in contrast, one makes the wrong choices, one's body-machine will be neglected, rusty, and low-functioning. The workers in one's own body will operate under no instructions from a knowledgeable, rational authority. Instead of maintaining an already functioning machine, these workers scatter over its entire width and appear more as though they are trying to salvage it from total destruction.

In what seems an almost too literal representation of the Foucauldian subject-machine, the successful homo economicus, represented by the muscular torso, demonstrates the correct management of this man's capital. His machine, his ability to work, which "cannot be separated from the worker himself" (Foucault, 2008, p. 224), is given proper care in order to ensure that the human capital in question will be at a maximum. The fit man also serves to represent the image's imagined visitor and target audience, the economic subject who has incorporated this valuable knowledge and has accordingly responded "in a non-random way, in a systematic way" (Foucault, 2008, p. 269). Systemic here means rational, or rationalistic, as in Val Plumwood's critique of the neoliberal market logic (Plumwood, 2002, p. 14).

Rationality, or rationalism, is a central notion in the self-management of the homo economicus. The ability to adjust and respond to information provided ensures that the homo economicus' enterprise functions under the best possible regulation. As Thomas Lemke explains in "The birth of bio-politics: Michel Foucault's lecture at the Collège de France on neo-liberal governmentality" (2001),

"Awarded with 'absolute' liberty regarding the maintenance of themselves, neoliberal subjects must now prove worthy of this gift, by demonstrating their best possible behaviour in their management of their lives. According to Foucault, this neo-liberal homo economicus 'becomes a behavioristically manipulable being and the correlative of a governmentality which sys- tematically changes the variables of the 'environment' and can count on the 'rational choice' of the individuals." (p. 13)

Thus, the neoliberal homo economicus is left to operate in a field of seemingly endless freedom, unaware of the fact that all of his supposedly informed and rational manoeuvres are the direct results of a specifically framed 'regime of truth', where 'truth' is formed and authorised in particular manners.

The websites we will analyse in this essay are examples of the kinds of places where that 'truth' about embodied rationalism is generated and distributed. The websites themselves base their arguments on specific biomedical narratives about fatness. They also function as a bridge between scientific discourse and the public under the promotion of the state. However, it is not the responsibility of any state to enforce rational conduct on its citizens; the state is only there to provide them with the knowledge needed for them to conduct themselves in the expected rational way.

Current literature within fat studies has taken up the analysis between the individual fat body and the neoliberal machine. Scholars such as Paul Campos (2005) and J. Eric Oliver (2006) have taken critical stances to analyse the current epidemiological obesity discourse. These critical approaches are centred on debunking commonly held medical 'facts' about 'obesity' and analysing obesity as a social rather than a medical issue. However, by insisting that we employ the terms 'obesity' and 'obese', such work errs on two levels. In criticising Campos for substituting "good" science with "bad" science, Michael Gard (2008) points out how these scholars continue to uncritically subscribe to a problematic, positivist ideal of health morality, and Charlotte Cooper, in "Mapping the Field" (2010), comments on the "scientific" distance this body of work seems to have from its fat subjectsfatness remains a topic that needs to be discussed and spoken for by removed, "objective" experts. This article instead wishes to continue the approach outlined in the Fat Studies Reader (2009), edited by Esther Rothblum and Sondra Solovay, where, in close dialogue with fat activism, fat scholars speak for themselves, politicising, theorising, and analysing through their embodied experience as surviving subjects within neoliberalism. The analysis that thus follows will do its best to avoid any notion of a detached, medical view, and instead dive into the examination of the object in a constant dialogue with our own embodiment.

The image of the fat man's torso in the picture delivers a powerful message: the body is a machine for which the subject is responsible. Faced with the freedom of choosing between apples and fries, working out and burgers, the subject finds two separate paths: the first is the path of rationality and responsibility, which will guarantee optimal results for the body-machine-results that will be reflected both on the inside (the shiny machine itself) and on the outside (the muscular body which is 
directly proportionate to the condition of the machine). The second path is the antithesis of the first-on this road, the subject fails to embody neoliberal rationalism in several ways: the fat torso betrays the systemic laws of efficient and goal-oriented labour, and the workers in the fat body work without a plan, lacking scientific, technocratic methods. He fails to succeed as a neoliberal working subject, and fails to fulfil his public function by potentially creating a threat to the functioning of the larger "machine" of society. Here, fatness becomes the signifier not only for the dysfunctionality of the individual body, but also for the rationalistic world providing this body with (failed) opportunities. The image of the fat man functions as a cautionary tale for the website's visitor: this is what will happen to your machine, your capital, your role in society, as well as your humanity, if you neglect your economic responsibilities as a neoliberal subject.

Nevertheless, it would be short-sighted to identify the website's visitors entirely with the image of the fit man, and to position the fat man as only a cautionary figure. If that were the case, the website itself would be redundant. In a more nuanced metaphor, we think it is possible to claim that there are three planes of existence within which the visitor, the fit man and the fat man, reside. Drawing from religious imagery, we would say that on the left side of the image lies Heaven-a productive, well-adjusted, rational, well-functioning neoliberal Heaven. Even the colours of the left side of the image, the steel-coloured whiteness, and the shiny machinery seem to suggest this. On the right side lies Hell-dumpy, grey, rusty, malfunctioning Hell. And right in the middle, right where the visitor is unconsciously positioned, lies Purgatory. The visitor is most likely not as shiny, muscular, or fit as the man on the left. However, based on the tone and the content of the article that accompanies these images, the visitor is also not assumed to be the lost cause that is the man on the right. Instead, the visitor is trapped in Purgatory, standing at the crossroads, repenting for old sins, and thus his inability to enter Heaven, but not having yet committed the penultimate crime of forsaking selfmanagement, and so not quite in Hell. Which road will the visitor choose: the one that offers a shiny, nutritious apple? Or the other, which presents a greasy, unhealthy hamburger? The religious undertones of such a reading of the image inevitably bring us to the question of who might be the 'priest' of this 'religion', as well as what this 'religion' actually entails. In the following parts, we will utilise Nikolas Rose's theory on pastoral power in order to explore the first part of the question, about the neoliberal religion's priest.

\section{Pastoral Power and Homo Economicus}

In The Politics of Life Itself (2007), Nicholas Rose writes about pastoral power that it

"is not organized or administered by 'the state....It takes place in a plural and contested field traversed by the codes pronounced by ethics committees and professional associations, by the empirical findings generated by researchers, the attitudes and criteria used by employers and insurers, the tests developed and promoted by psychologists and biotech companies, the advice offered by self-help organizations, and even, one might add, the critical perspectives contributed by religious organizations and sociological critics." (p. 73)

When trying to identify which organising field of pastoral power HFR uses, our first reaction was to identify it as a 'self-help' organisation. The website does not posit itself explicitly as such. It does not pose as a help manual; it proposes a 'revolution'. We believe that this perception of the website's disposition has to do with the tone of a subtext that posits the website as there to "help you help yourself". What is, however, important about pastoral power and its practice is that it is relational, not unidirectional. Using human reproduction as an example, Rose describes how,

"[Pastoral Power] works through the relation between the affects and ethics of the guider-the genetic counsellors and allied experts of reproduction who operate as gatekeepers to tests and medical procedures-and the affects and ethics of the guided - the actual or potential parents who are making their reproductive decisions, and their networks of responsibility and obligation." (2007, p. 74)

Thus, the website's decision to position its visitor as an already properly functioning, rational subject can be interpreted as a strategic move in the practice of pastoral power. The website "pretends" that it is not there to lecture, but to have a friendly conversation between equals. Pastoral power enables the creation of a series of microtechnologies, which-unlike the sovereign power model, which requires a knowledgeable lecturer and a submissive receiver-place participants on a reciprocal level.

As pastoral power is two-directional, we cannot speak of one of its ends without taking into account its other. However, we would argue that, in the example of the HFR website, the perceived 'pastor' of the interaction is the main focus. Although we could extract a number of observations about the website's visitor through the way the website is designed, he or she does not have a direct voice in the discussion. For that reason, we decided to offer a second case, an online community called Reddit. Using this community, we will explore what happens when the authority shifts from a perceived 'expert' to the 'general public', and explore the different kind of divisions that this shift creates.

Reddit is an online platform comprised of hundreds of forums, called 'subreddits', all of which have been created and are continuously moderated by users. Material in the subreddits is also user-generated; users can 
post links to articles, images, and videos, or submit an original text of their own writing. Every subreddit has its own theme, its own rules, its own etiquette, and, often, its own Wiki page. One can usually find the rules and Wiki page, as well as links to previous, archived posts that could prove useful for a new user in the sidebar of the page.

The subreddits we will analyse here form a constellation, within which all contributions are explicitly dedicated to fat hatred, approached from different angles. Users can choose to share stories of how ridiculous fat people are in fatpeoplestories, they can share examples of fat people's lack of rationality in fatlogic, or-if they just want to let it all out-go for fatpeoplehate. Some would argue that Reddit is a particularly harsh place, and that the explicit hatred expressed in those subreddits is not indicative of the rest of society. We would instead argue that Reddit is nowhere near the harshest place in the Internet world. Places such as $4 c h a n^{2}$ and Stormfront ${ }^{3}$ take the proverbial cake and eat it before Reddit has even had time to lift its fork. We argue that Reddit, as a democratically functioning platform where anyone can express anything, simply allows its users to be more explicit about the assumptions under which they operate in everyday life. From the experience of one Reddit author as a fat person, the only difference between the attitude of Reddit users to the ones the author encounters in everyday life is the opacity with which the assumptions are put to use. While in everyday life these assumptions function in a polite subtext, the anonymity of Reddit brings them to the surface in all their explicitness.

On the sidebar of fatpeoplestories, one can find the rules of what constitutes a good 'fat people story'. This is the first place where we detected an interesting dichotomy, 'Hamplanets vs fat people'. According to the sidebar, "This sub is a place for you to tell us about hamplanets in your life and your relationships/encounters with them. Remember that hamplanet is not just about the weight, but also the hamentality-rudeness, entitlement, fatlogic, etc. Not all fat people are hambeasts but all hambeasts are fat people". This issue is further explored by the users of the subreddit. In a submission appropriately titled "Hamplanets vs fat people" (2013), user KangK brings up a quote by Roald Dahl, which would not normally be expected to appear in a place dedicated to fat hatred. The user's submission reads:

"If a person has ugly thoughts, it begins to show on their face. And when that person has ugly thoughts every day, every week, every year, the face gets uglier and uglier until you can hardly bear to look at it. A person who has good thoughts can never be ugly. You can have a wonky nose and a crooked mouth and a double chin and stick out teeth, but if you have good thoughts it will shine out of your face like sunbeams and you will always look lovely. (Roald Dahl, The Twits, 1979)
I feel like this quote is relevant when we distinguish between fat people and hamplanets. After all, so long as the fat person doesn't have absurd logic or a ridiculous sense of entitlement, we don't consider than [sic] hamplanets, do we? They are not the people that we are criticising." (KangK, "Hamplanets vs fat people", n.d.)

User MCprofK replies: "I love this subreddit, but I must be honest that some things that it stands for aren't entirely clear from the start. Now, I won't try to speak for the entire sub, but this is our opinion. Fat people are disgusting. But this is the thing....To me, to be truly a 'fat person' you have to have the fat mentality, or simply not realize it at all, and accept none of the guilt" (MCprofk, "Hamplanets vs fat people", n.d.).

Let us make the distinction between 'hamplanets' and fat people more comprehensible. According to this approach, there are fat people, and they are deemed repulsive. However, there exists a hierarchy in how repulsive they are: to be deemed a 'hamplanet', he or she must also be characterized by self-entitlement and rudeness, and afflicted by fatlogic. The standing definition of fatlogic in the UrbanDictionary (n.d.) reads:

"The astounding mental gyrations obese people use to justify their size. Fatlogic never, ever includes eating too much and exercising too little.

'Fatlogic insists that five triple cheeseburgers doused with mayonnaise are balanced by a diet soft drink.' 'I'm not fat, I'm just large-boned.'

'I have a condition; I gain weight for no reason at all.'Said when finishing the fourth bag of cookies before noon."

Whereas in everyday life fat people are concernedly reprimanded for their health-choices and self-management, here, in the seeming safety of the internet, the advisory tone is crystallised into an underlying question: where is your logic? Since the pastoral power exercised by the websites, specialists, dieticians, doctors, and diet bloggers have made the dangers of fatness entirely clear, 'hamplanets' must be operating under a completely different set of rules, a warped and greasy logic that prevents them from seeing things clearly. It stops them from utilising the information supplied to rationally manage themselves and adjust, adapt, and manipulate themselves to ensure the worth of their capital, enjoy the benefits of self-regulation, and, by extension, offer these benefits to the rest of society. Here, we would like to point out how claiming the existence of some inherently negative qualities that fat people share-qualities that function as the reasons for any hatred expressed towards fatness-echoes fat persons' failure to properly regulate themselves, this time as social beings, while allowing the

\footnotetext{
${ }^{2}$ www.4chan.org

${ }^{3}$ www.stormfront.org
} 
hater to relinquish all responsibility for his or her "attitude". Like the website in our first analysis, the users of this site would have us believe that the focus is not even on fatness itself. It is on all the repercussions that come with being fat. On the other websites, the repercussions were framed in terms of health. Here, they are framed in terms of being hideous. Interestingly though, the distinction between 'hamplanets' and fat people does not enjoy unanimous support. The highest upvoted comment in the submission reads: ${ }^{4}$

"To me, anyone who let's go of themselves to become obese has a problem, regardless of how pleasant they are. I can't hold them to equal esteem as I would other people, the same way I wouldn't hold someone who doesn't bathe and shave very highly. Taking care of yourself is a good indicator of how you deal with other situations, people who don't care about themselves are less likely to care about other standards." (KangK. "Hamplanets vs. fat people", n.d.)

Following this logic, by allowing themselves to get fat, people demonstrate how little they value the gift of freedom and self-regulation that neoliberalism has given us. By allowing their bodies to get fat, fat people have demonstrated their failure to rationally govern themselves, and should subsequently be ready to relinquish any claims to respect since they have already committed the ultimate act of disrespect towards themselves and, ultimately, towards humanity.

\section{Managing the Body and Manipulating the Body: Bioethics and Posthumanism}

In light of such neoliberal tendencies of self-enhancement, we wish to position posthuman theories, as well as their related technological practices aimed at human enhancement, in a critical, and possibly more complex, relationship to cultural conceptions of embodiment, such as fatness. One field of research, which promises to keep an overly one-sided trend towards human enhancement in check, is bioethics. Bioethics, as the term suggests, studies the critical relations between new developments in the "bio-sciences" and philosophical, as well as political and practical, questions of value, dignity, and care. In Bioethics in the Age of New Media (2009), Joanna Zylinska defines bioethics as a response to developments in biotechnology and medicine that raises "philosophical questions about the constitution of the boundaries of the human and human life, as well as considering policy implications of such developments for government bodies, health care institutions, and other social organs. It is thus always already a clinically driven 'expert discourse,' which can then be applied to 'real-life cases'” (p. 5).

However, despite bioethics' potential to keep certain technological developments and translation to everyday practice in check, critical bioethicists warn against the field's biased approach to notions of embodiment, human norms, and political goals. Zylinska explains that what binds differing approaches to bioethics is that they all embrace a sense of normativity, which is "filled with positive content" (p. 5); they call for universal and applicable moral judgements on the basis of "the rational human subject that can make a decision and that is seen as the source of this decision" (p. 5). The universalizing and normative standards of bioethical theories therefore seem to hide the fact that bioethics has become an integral component of neoliberal regulatory practices. In When Species Meet (2008), Donna Haraway even argues that bioethics "acts as a regulatory discourse after all the really interesting, generative action is over" (p. 136).

However, following Zylinska's timeline, bioethics also seems prescriptive, not just descriptive. It seems to generate a discourse that does not simply regulate the morality of what already exists, but dictates a type of morality of both the present and the future. In its role of regulating medical discoveries regarding the body, bioethics operates under the assumption that manipulating the body through science is an imperative, not a choice. When theorists such as Peter Singer go as far as to support "the distinction between a 'human being' and a 'person,' with only the latter, characterised by rationality and self-awareness, being worthy of ethical respect" (Singer quoted in Zylinska, 2009, p. 13), the 'person' in question is expected to be self-aware and rational, and thus to rationally choose to make use of current or future medical science to achieve the best possible results for his or her health. This assumption shows the existing relationship between rationality and morality within the field of bioethics itself. An irrational subject who would refuse to use these technologies would also fail morality, and therefore would not be worthy of ethical respect or 'personhood'.

The "hamplanets" of fatpeoplehate would directly fall under Singer's categorisation of 'human being', thereby falling outside 'personhood', as they have failed to demonstrate a sense of rationality and, by denying the guilt of their condition, have not exhibited selfawareness. We would like to stress here that Singer's differentiation between person and human being is a distinction in degrees that will necessarily create the likelihood for subjects to fall outside of both, which is how humanity is contested too-albeit in dangerous ways. Thus, by eventually failing in both of Singer's categories, fat subjects are logically "not worthy of ethical respect". Or one could see the fat subject's position somewhere between neither/nor, where both 'neither' (quite a person) and 'nor' (quite a human being) have been imbued with specific meanings. On this background, HFR assumes that a responsible, rational, and moral subject must maintain her or his position through an active attempt to sustain her or his good health. What happens,

\footnotetext{
${ }^{4}$ Depending on whether a user agrees or disagrees with a comment they can either upvote or downvote it by clicking the orange or the blue arrow next to it.
} 
though, if we take the moral responsibility of an already unattainable super-health and stretch it to its logical conclusion? Earlier, we mentioned the irreducibility of striving for what is 'good for you'. Here, constant technological innovations that target human enhancement irreducibly and seamlessly lead to a striving for what is 'even better for you'. And this irreducibility comes with its own extended morality. Zylinska explains the work of John Harris, a renowned supporter of human enhancement:

"Harris posits the need for enhancement as a universal 'moral imperative' and seems to have a very clear sense what this 'enhancement' actually means. His 'better people' will be more intelligent, more beautiful, but also 'longer-lived, stronger, happier, smarter, fairer (in the aesthetic and in the ethical sense of that term)' -in other words, 'more of everything we want to be'" (Harris quoted in Zylinska, 2009, p. 14)

Human (prosthetic) enhancement is thus positioned as merely the next step to which the trifecta of responsibility, rationality, and morality should aspire and comply. What we aim to highlight here is that bioethics does not merely function as retroactive (or even passive), as Haraway seems to suggest, but as pro-active and influential on the discourse at-large. Technology, science, and their medical consequences are decidedly placed as the most important factors in identifying who passes as a human being. Bioethics is therefore not only concerned with current practices, but is also instrumental in imagining future advancements and their moral implications. This imagined future, to some degree, takes place within posthumanism, a field that, while distinct from bioethics, shares many of its concerns and imageries. Both bioethics and posthumanism are concerned with what counts as personhood; bioethics works to delineate it, and posthumanism to expand it. Both fields share a fascination with technological advancements and a relation to the body; bioethics is more focused on regulation, and posthumanism on anticipation. A fundamental difference between the two fields is that bioethics seeks to categorise, while posthumanism aims to destroy boundaries and blur distinctions. However, even within the field of post humanism-and with all of its critical good intentions-notions of responsibility, rationality, and morality continue to hide behind many celebratory anticipations of prosthetic bodily enhancement and cyborg embodiment. We would like to thus venture into this field and problematize the areas in which such biopolitical narratives are reproduced in posthumanist discourse, using fatness as our shining "b(e)acon". Our main focus will be on prosthesis as both metaphor and materiality, and the ways in which, as demonstrated by Harris, it becomes a societal imperative (Harris quoted in Zylinska p. 14). The fat body, as mentioned in the introduction, here serves as the limit case ${ }^{5}$ for both posthuman theory and a project of contesting humanity. The concept of prosthesis, as inspired by the works of Jain (1999) and Sobchack (2006), signifies both human enhancement and inhuman differentiation between bodies termed "worthy" or "unworthy" of human life.

Before we continue with our analysis around fatness and posthuman bodies, we feel the need to outline our understanding of what posthumanism is and how bodies and prostheses function within it. There seem to be as many definitions of posthumanism as there are articles about it, and the same is true for approaches to the concept of prosthesis. In Discipline and Practice: The (Ir)Resistibility of Theory (2004), Herbrechter and Callus identify as many as six impossible things before breakfast-six types of post humanism-while articles such as Damien Broderick's "Trans and Post" (2013) indicate the tensions that exist within the discipline itself, with representatives of different branches of posthumanism attempting to delineate their approaches and distance them from or position them against those of others.

Our own understanding of posthumanism is informed by several texts, the central of which is Katherine Hayles' volume How We Became Posthuman: Virtual Bodies in Cybernetics, Literature, and Informatics (1999):

\begin{abstract}
"What is the posthuman? Think of it as a point of view characterized by the following assumptions....First, the posthuman view privileges information pattern over material instantiation, so that embodiment in a biological substrate is seen as an accident of history rather than an inevitability of life. Second, the posthuman view considers consciousness, regarded as the seat of human identity in the Western tradition long before Descartes thought he was a mind thinking, as an epiphenomenon, as an evolutionary upstart trying to claim that it is the whole show when in actuality it is only a minor sideshow. Third, the posthuman view thinks of the body as the original prosthesis we all learn to manipulate, so that extending or replacing the body with other prostheses becomes a continuation of a process that began before we were born. Fourth, and most important, by these and other means, the posthuman view configures the human being so that it can be seamlessly articulated with intelligent machines." (pp. 2-3)
\end{abstract}

The body becomes "the original prosthesis", a body to be manipulated by the subject, according to her or his wishes - a body to be fused, extended, and imbued with social meaning and function. In this sense, we find that there is a definite overlap between what is expected of a homo economicus and a posthuman subject regarding their bodies. Where the homo economicus is expected to rationally manage his or her body in order to secure his or her well-being, the posthuman subject is expected to manipulate his or her body in order to remain faithful to the ongoing evolution of prosthetic embodiment.

\footnotetext{
${ }^{5} \mathrm{~A}$ case that tests the theory as well as humanity because of its extreme/special relation to both.
} 
Whereas the homo economicus should aspire to maintain his body in the best possible condition, the post human subject should now aspire to expand the body to the best imaginable position by allowing the inclusion of cybernetic mechanisms. Management refers to reality, to the existing means and resources and their allocation, while manipulation extends management to the realm of possibilities and imagination.

In her article, "The Prosthetic Imagination: Enabling and Disabling the Prosthetic Trope" (1999), Sarah S. Jain argues that the ways in which the trope of the prosthesis is theorised promotes "the notion that the prosthesis compensates for some sort of physical disabilityalthough this disability may be in relation only to the realm of the possible rather than a handicap in the way in which it is classically conceived" (p. 33). Thus, no matter how alluring the idea of a posthuman subject without boundaries may be, it seems that, in many of its appearances, the trope of the prosthesis does not truly transgress or eradicate, but instead reinforces and multiplies the restrictive expectations that surround the neoliberal subject.

As Jain further explains, when used uncritically, the trope of the prosthesis entails two dangerous assumptions: first, that a disabled or non-able body is inherently flawed and needs correction, and, second, that all bodies are potentially disabled when juxtaposed with their posthuman, enhanced possibilities. In this manner, the biopolitical body-machine relation stays firmly in place. The body is still subjected to the same kind of imperative that demands its placement under constant moral, rational, and responsible social imperatives. In the biopolitical context, Skrabanek speaks of super-health (1994, p. 42), and HFR positions its viewer between a frumpy Hell and a shiny Heaven. This narrative is present in many prosthetic imaginations, where subjects find themselves not only morally responding to the realm of the possible but also to that of the imaginary. The end result in both cases is a subject with a body machine that requires constant modification. If we were to follow Singer's distinctive logic of the human being versus the person, both homo economicus and the posthuman subject would find themselves in a position where they have to earn their right to ethical respect while simultaneously struggling to remain within the human category.

Homo economicus is, then, the condition for the human subject, while the enhanced body becomes the condition for the posthuman subject. When the prosthetic imagination is allowed an uncritical and central role in posthuman embodiment, it comes to reinforce the same boundaries posthumanism wishes to transgress while simultaneously strengthening neoliberal narratives that oppress the body. Again, the posthuman subject needs to be rational and recognise its insufficiency compared with its prosthetic capabilities. It must be responsible, and take action towards achieving its potentiality. Finally, it must be moral, as morality requires one to combine rationality and responsibility. If it seems we are vindictively rubbing our hands together, it is becausemetaphorically-we are. Return to our reading of the HFR image and its positioning of the viewer as neither in Heaven nor in Hell. Now add posthuman fantasies to the mix, and we get a highly satisfying procedure when the aim is to blur categorical boundaries. With prosthetic enhancement at the centre of current bioethical discussion, Jain's argument demonstrates how easily the perceived viewers of HFR can slip from their comfortable Purgatory straight into Hell if they fail to adapt and rationally respond to this renegotiation of neoliberal ideology. In the health/fitness versus illness/fatness schema, viewers can feel confident in their responsibility, rationality, and morality. This time, however, when responsibility, rationality, and morality are expanded ad infinitum, where do viewers find themselves on the human vs. failed human scale?

In The Fat Studies Reader (2009), Marilyn Wann describes fat/fatness as "a floating signifier, attaching to individuals based on a power relationship, not a physical measurement" (p. xiv). In this paper, we attempted to paint a prosthetic nightmare. We took the theoretical characteristics of the prosthetic trope, turned them around, and demonstrated how they can be applied in imagining a prosthesis that renders the body, and thus the subject, not more, but less human. By positioning fatness as itself a kind of "prosthesis", we intended to point out how -if we add posthumanism to neoliberal ideals - a fat subject can crumble beneath the weight of her or his now supersized, double failure. As homines economici, fat subjects fail to optimally manage themselves; as posthuman beings, they fail to adapt to the evergrowing, accelerating capabilities of the human body. Unlike most prosthetic narratives, the fat body as prosthetic embodiment is no longer something that makes the body faster, stronger, and more productive, thus 'improving' it, but something that hinders its productivity and reflects negatively on its owner's ability to successfully manage and manipulate the body's own place in the category of the human.

\section{Conclusion}

In conclusion, we will attempt to paint a hopefully less nightmarish image of contested humanity by proposing an outlook for the development of different strands of embodied theory that take seriously the impact critical versions of posthumanism and disability theory may make on dominant bodily beliefs and practices. We want to ask what, if anything, could a critical posthumanist and disability studies approach inject into the just painted nightmare? Certainly the most productive theoretical contributions to challenge neoliberal biopolitics have come from critical engagements with marginalised embodied experience and subjectivity, such as in feminist, queer, critical race, and disability studies. However, as recent trends in interdisciplinary humanities research have proven (new materialism, critical posthumanism), 
an engagement with the non-human, material, animal, planetary, and ecological entanglement of human bodies with the world is similarly crucial to a critical discourse of human life.

What this paper attempted was a dialogue between embodied human difference and more-than-human material practices (technologies) as they have been powerfully incorporated into neoliberal ideology. What remains to be further explored and-hopefully-critically embedded in a future body-politics is a discourse that contests more concretely what Astrida Neimanis has described as "a neoliberal, individualistic reproductive imaginary of commodification and amnesiac bioscientific progress" (2014, p. 109), which fosters discrimination against bodily difference and is primarily focused on preservation of the self-same. A counter-discourse will need to take a critical stance towards all-too-human, rational, technical, progressive, and linear expressions of human futures, and take seriously a more-than-human, affective, transcorporeal, elusive, and messy imaginary of embodied lives.

Fat studies, disability theory, and a critical take on posthumanist theory are but a few ways to sketch a more inclusive future for those who contest not humanity as such, but a neoliberal propagation of seemingly humane cultural practices.

\section{Conflict of Interests}

The authors declare no conflict of interests.

\section{References}

Badmington, N. (2003). Theorizing posthumanism. Cultural Critique, 53(1), 10-27.

Broderick, D. (2013). Trans and post. In M. More \& N. VitaMore (Eds.), The transhumanist reader: Classical and contemporary essays on the science, technology, and philosophy of the human future (pp. 430-437). New York: Wiley-Blackwell.

Campos, P. F. (2004). The diet myth: Why America's obsession with weight is hazardous to your health. New York: Gotham.

Cooper, C. (2010). Fat studies: Mapping the field. Sociology Compass, 4(12), 1020-1034.

Dahl, R. (1997). The Twits. In The Roald Dahl Treasury. London: Random House.

Foucault, M. (2008). The Birth of Biopolitics: Lectures at the Collège de France, 1978-79. New York: Palgrave Macmillan.

Gard, M. (2008). Friends, enemies and the cultural pol- itics of doing critical obesity research. In J. Wright \& V. Harwood (Eds.), Biopolitics and the obesity epidemic: Governing bodies (pp. 31-44). London: Taylor \& Francis.

Hamplanets vs fat people. (n.d.). Retrieved from https://www.reddit.com/r/fatpeoplestories

Haraway, D. J. (2008). When species meet. Minneapolis, $\mathrm{MN}$ : University of Minnesota Press.

Hayles, K. (1999). How we became posthuman: Virtual bodies in cybernetics, literature, and informatics. Chicago, IL: University of Chicago Press.

Herbrechter, S., \& Callus, I. (2004). Discipline and practice: The (ir)resistibility of theory. Lewisburg: Bucknell University Press.

Jain, S. S. (1999). The prosthetic imagination: Enabling and disabling the prosthesis trope. Science, Technology \& Human Values, 24(1), 31-54. doi:10.1177/ 016224399902400103

Lemke, T. (2001). The birth of bio-politics: Michel Foucault's lecture at the Collège de France on neo-liberal governmentality. Economy and Society, 30(2), 190207.

Neimanis, A. (2014). Speculative reproduction: Biotechnologies and ecologies in thick time. philoSOPHIA, $4(1), 108-128$.

Oliver, J. E. (2006). Fat politics: The real story behind America's obesity epidemic. New York: Oxford University Press.

Plumwood, V. (2002). Environmental culture: The ecological crisis of reason. London: Routledge.

Rose, N. S. (2007). Politics of life itself: Biomedicine, power, and subjectivity in the twenty-first century. Princeton: Princeton University Press.

Rothblum, E., \& Solovay, S. (2009). The fat studies reader. New York: NYU Press.

Skrabanek, P. (1994). The death of humane medicine and the rise of coercive healthism. London: Social Affairs Unit.

Sobchack, V. (2006). A leg to stand on: Prosthetics, metaphor, and materiality. In M. Smith \& J. Morra, The prosthetic impulse: From a posthuman present to a biocultural future (pp. 17-41). Cambridge, MA: MIT Press.

Urban Dictionary. (n.d.). Fatlogic. Retrieved from http://www.urbandictionary.com/define.php?term= fatlogic

Wann, M. (2009). Foreword: An invitation to revolution. In E. Rothblum, \& S. Solovay (Eds.), The fat studies reader. New York: NYU Press.

Zylinska, J. (2009). Bioethics in the age of new media. Cambridge, MA: MIT Press. 


\section{COGITATIO}

\section{About the Authors}
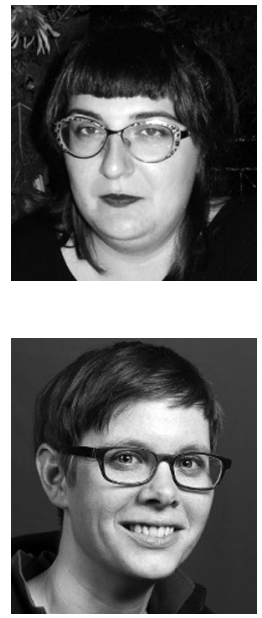

Sofia Apostolidou studied Philology at the Aristotle University of Thessaloniki and Cultural Analysis at the University of Amsterdam. She is currently a PhD candidate at the Amsterdam School for Cultural Analysis. Her research interests include fatness, posthumanism, modernities, and different embodiment paradigms. She is a member of the activist/performance groups "Fatties from Hell" and "Political Fatties", based in the Netherlands and Greece respectively. Through workshops, screenings, performances, and publications, the groups are attempting to build a network that opens up the discourse around the various intersections bodies can inhabit.

Jules Sturm is assistant professor in Literary and Cultural Analysis at the University of Amsterdam (Netherlands). Jules' research focus is on critical theories of the body. Originally trained in philosophy and women's studies, Jules extended her/his fields of interest to Theories of Art and Aesthetics, Queer Theory, Posthuman Theories, Phenomenology, and, more recently, Critical Disability Studies and Medical Humanities. In teaching and in writing, Jules' goal is to explore new methodologies in the humanities to account for the as yet unknown, but impending futures of human and non-human bodies. 